\title{
A fast and accurate two-stage strategy to evaluate the effect of the pin tool profile on metal flow, torque and forces in friction stir welding
}

\author{
N. Dialami, M. Cervera, M. Chiumenti and C. Agelet de Saracibar \\ International Center for Numerical Methods in Engineering (CIMNE), \\ Technical University of Catalonia, Module C1, North Campus \\ C/ Gran Capitán s/n 08034 Barcelona, Spain \\ E-mail addresses: narges@cimne.upc.edu (N. Dialami), \\ Miguel.Cervera@upc.edu (M. Cervera),michele@cimne.upc.edu (M. Chiumenti), \\ agelet@cimne.upc.edu (C. Agelet de Saracibar)
}

\begin{abstract}
Pin geometry is a fundamental consideration in friction stir welding (FSW). It influences the thermal behaviour, material flow and forces during the weld and reflects on the joint quality.

This work studies four pin tools with circular, triflute, trivex, and triangular profiles adopting a validated model of FSW process developed by the authors. The effect of the rotating tool geometry on the flow behaviour and process outcomes is analysed. Additionally, longitudinal and transversal forces and torque are numerically calculated and compared for the different pin shapes. The study is carried out for slip and stick limiting friction cases between pin and workpiece.
\end{abstract}

The main novelties of the paper are a "speed-up" two-stage simulation methodology and a piecewise linear version of the constitutive model, both of them conceived for the use in real case industrial applications, where the achievement of accuracy with affordable simulation times is of importance.

The Norton-Hoff constitutive model is adopted to characterize the material behaviour during the weld. The piecewise linear version of the model developed by the authors greatly facilitates the convergence of the numerical solution ensuring both computational efficiency and accuracy. A two-stage computational procedure is applied. In the first stage, a forced transient is carried out; in the second one, the magnitudes of interest are computed.

The study shows that the proposed modelling approach can be used to predict and interpret the FSW behaviour for a specific pin geometry. Moreover, the reduction of the simulation time using the two-stage strategy can be up to $90 \%$, compared to a standard single stage strategy.

Keywords: Pin profile, FSW, Friction, Force, Torque, Temperature 


\section{Nomenclature}

\begin{tabular}{|ll|}
\hline $\mathbf{s}$ & Stress deviator \\
$p$ & Pressure \\
$\rho_{0}$ & density in the reference configuration \\
$\mathbf{b}$ & body forces vector per unit of mass \\
$\mathbf{v}$ & Velocity field \\
$\mathbf{\sigma}$ & Cauchy's stress tensor \\
$\dot{\boldsymbol{\varepsilon}}$ & Strain rate \\
$\mu_{\text {eff }}$ & Effective viscosity \\
$c$ & Specific heat \\
$T$ & Temperature \\
$\mathbf{v}_{\text {mesh }}$ & Velocity of the mesh \\
$k$ & Thermal conductivity \\
$\beta$ & Fraction of plastic dissipation \\
$h_{\text {conv }}$ & Heat transfer coefficient by convection \\
$h_{\text {cond }}$ & Heat transfer coefficient by conduction \\
$\sigma_{\text {rad }}$ & Stefan-Boltzmann constant \\
$\varepsilon_{\text {rad }}$ & Emissivity factor \\
$\alpha$ & Speed-up factor \\
$T_{\text {env }}$ & Environmental temperature \\
$T_{\text {tool }}$ & Tool temperature \\
& \\
\hline
\end{tabular}

\section{Introduction}

In Friction Stir Welding (FSW), a rotating tool with a specifically designed shape and profile is inserted into the weld line, where it moves forward and generates heat. The FSW tool is responsible for the frictional heating and the mechanical mixing. The features on the pin are designed to improve the flow of the material and to facilitate mixing phenomena, therefore affecting the mechanical properties of the welded material $[1]$.

The pin is designed to disrupt the contacting surfaces of the workpiece, shear the material in front of the tool and move the material behind the tool. The depth of deformation and the choice of tool traveling speed are mainly governed by the pin. The pin serves two primary functions: heating of the workpiece and moving the material to produce the joint. Both the heat and the material transfer depend on the workpiece material properties, tool geometry, and FSW process parameters. Therefore, it is of practical importance to optimally design the pin choosing an appropriate geometric shape in order to obtain high quality welds. 
Since FSW is a solid-state welding technique, the design of the pin tool requires insight of the material flow from the front of the pin to the rear during the weld. During the past decade, FSW studies have been focused on the welding method and temperature distribution [2-7], microstructure of the welded joint [8-9], material flow visualization [10-13], and residual stresses [14-16]. The forces that the pin tool experiences during the FSW process have been studied by Reynolds et al. [17], who reported force and weld energy measurements made under controlled FSW process parameters (e.g. rotational velocity and welding speed), tool geometry and alloy type.

Extensive experimental studies on the effect of the tool shapes have been carried out [18-21]. These have demonstrated that the tool profile shape has a significant effect on the macrostructure [18-19], microstructure [21], welding force [18], and mechanical properties $[19,21]$ of the joint. It has been found that the joint structural properties can be improved when using a featured non-cylindrical pin compared to the traditional cylindrical pin [26].

Despite the fact that the tools design influences the weld properties and the forces, they are still designed empirically by trial and error. The systematic design of the tools based on scientific principles has been started only recently.

Numerical simulation provides a quantitative understanding of the heat generation and material flow. Colegrove et al. [22] described the application of the FLUENT to model the metal flow in FSW to the plain 'Trivex', the threaded 'MX-Trivex' and the 'MXTriflute' tool. They showed that the different pin designs had little effect on the heat input and the tensile strengths of the welds were comparable.

In the work of $\mathrm{Su}$ et al. [23], a numerical method was employed to quantitatively analyse the thermo-physical phenomena in FSW with two tools of different pin shapes (axisymmetrical conical tool and asymmetrical triflat tool). The total heat generation, heat density and temperature distribution during the welding process with triflat tool were elucidated and compared with that of conical tool, and the material flow patterns and deformation regions of various pin orientations were exhibited in detail. It was found that the deformation zone caused by triflat tool was larger than that corresponding to conical tool, which was confirmed by the weld macrographs.

Hasan et al. [24] used FLUENT to study the differences in the flow behaviour, size of mechanically affected zone and strain rate distribution around unworn and worn tool 
geometries. Comparisons were made considering two different tool rotational velocities using a single weld transverse speed. The study demonstrates significant differences in the flow behaviour around the tool when it is worn and its profile is therefore modified.

Despite of the several attempts to analyse FSW with various tool profiles, some important features have not been considered yet. Usually, the contact between the tool and the workpiece is modelled as full sticking. In reality, a certain degree of slipping is known to exist between the pin and the workpiece, because of the reduction of the material flow stress with the increase of temperature.

Moreover, most of the models presented consider steady-state conditions with a fixed tool configuration instead of a periodic state where the real revolution of the tool is studied. Since in the case of an asymmetrical pin the tool-workpiece interface is changing constantly, a transient model is more appropriate to evaluate the flow characteristics during the rotation of the tool.

The objective of this work is to study the effect of pin geometry on the weldability, forces and torque at the periodic state of FSW, considering the friction at limit cases (perfect stick and slip). The underlying numerical method used in the present work has been extensively validated in previous works by the authors, including comparison with experiments and other numerical models $[2,4,6,14]$. The main novelty of the paper are the "speed up" two-stage methodology and the piecewise linear version of the constitutive model, both of them conceived for the use in real case industrial applications, where the achievement of accuracy with affordable simulation times is of essential importance. The work focuses on the analysis of the effect caused on the process behavior by the change of the pin shapes in the two limit frictional conditions. The presented results include temperature, material behavior, forces and torque for both stick and slip cases. This provides very useful qualitative and quantitative information, obtained with enhanced accuracy thanks to the developed numerical tool, for the practical in-between friction cases.

The outline of this paper is as follows: section 2 is devoted to the solution strategy used for the simulation of FSW. Section 3 describes the developed constitutive model for improving the convergence rate of the numerical scheme and decreasing the CPU time. The enhanced friction law applied at the pin-workpiece interface is explained in section 4. In section 5 an example with four types of pin shapes is modelled and their effect on 
the magnitudes of interest is discussed. Section 6 applies the proposed strategy to a 3D FSW model and compares 2D versus 3D FSW simulations.

\section{The solution strategy}

In this work, the analysis focuses on a small region surrounding the pin and the Thermo-Mechanically Affected Zone (TMAZ) (see figure 1). The pin is rotating with a constant speed around its fixed axis while the workpiece advances with an imposed velocity in the weld direction. The transient thermo-mechanical problem is strongly coupled as, on the one hand, the plastic dissipation and friction are the driving mechanisms for heat generation and, on the other hand, the material properties are highly temperature dependent.

The main parameters characterizing the FSW process are the rotation and welding speeds and the tool geometry. The focus of FSW analysis is the relationship between the process parameters and the corresponding heat generation, as well as the feasibility and quality of the final joint $[2-7,10,14,16]$.

The formulation used for the definition of the problem is summarized in table 1. The nomenclature is given at the beginning of the article. For a detailed explanation of the computational framework see ref. $[6,7]$.

Table 1: Formulation

\begin{tabular}{|c|c|}
\hline \multicolumn{2}{|c|}{ Mechanical partition } \\
\hline$\nabla \cdot \mathbf{s}+\nabla p+\rho_{o} \mathbf{b}=\mathbf{0}$ & Momentum balance equation \\
\hline$\nabla \cdot \mathbf{v}=0$ & Continuity equation \\
\hline $\boldsymbol{\sigma}=p \mathbf{I}+\mathbf{s}$ & Stress split \\
\hline$\dot{\boldsymbol{\varepsilon}}=\nabla^{S} \mathbf{v}$ & Kinematic equation \\
\hline $\mathbf{s}=2 \mu_{e f f} \dot{\boldsymbol{\varepsilon}}$ & Constitutive equation \\
\hline \multicolumn{2}{|c|}{ Thermal partition } \\
\hline$\rho_{0} c\left(\frac{1}{\alpha} \frac{d T}{d t}+\left(\mathbf{v}-\mathbf{v}_{\text {mesh }}\right) \cdot \nabla T\right)+\nabla \cdot \mathbf{q}=D_{\text {mech }}$ & Energy balance equation \\
\hline $\mathbf{q}=-k \nabla T$ & Heat flux \\
\hline$D_{\text {mech }}=\beta \mathbf{s}: \dot{\mathbf{e}}$ & Viscoplastic dissipation \\
\hline$q_{c o n v}=h\left(T-T_{e n v}\right)$ & Heat convection \\
\hline$q_{\text {cond }}=h_{\text {cond }}\left(T-T_{\text {tool }}\right)$ & Heat conduction \\
\hline$q_{\text {rad }}=\sigma_{\text {rad }} \varepsilon_{\text {rad }}\left(T^{4}-T_{e n v}^{4}\right)$ & Heat radiation \\
\hline
\end{tabular}


In this work, the apropos kinematic framework proposed in [3, 4] is used. A combination of ALE, Eulerian and Lagrangian descriptions at different parts of the computational domain is applied together with an efficient coupling strategy. Within this approach, a Lagrangian formulation is used for the pin, an ALE formulation is used at the stir zone of the work-piece (TMAZ), and an Eulerian formulation is used in the remaining part of the work-piece. The stir zone is defined as a circular domain close to the pin. The finite element mesh in the stir zone is rotating attached to the pin ( $\mathbf{v}_{\text {mesh }}=\omega \times \mathbf{r}, \omega$ being the rotational velocity of the pin tool and $\mathbf{r}$ the position vector with respect to the rotation axis). The resulting apropos kinematic setting permits to efficiently treat arbitrary pin geometries and facilitates the application of boundary conditions.

A fine mesh resolution is required in the TMAZ, where both the temperature and the strain rates gradients are very sharp, and the highly coupled non-linear behaviour of the constitutive law portrays the material.

Since performing a transient simulation starting from rest until achieving the periodic state requires to consider multiple revolutions (around 50 revolutions for typical process velocities), a 'speed-up' of the original procedure is developed here. This consists of two stages. In the first stage (speed-up), a simulation is performed aimed at reaching a steady-like state close to the final periodic state, particularly in the thermal field. In the second stage (periodic), the obtained steady-like state is taken as an initial configuration for the transient model (see figure 2).

The coupled thermo-mechanical problem described in table 1 is considered at both stages. As the Reynold's number is extremely small, inertia terms are neglected in the momentum equation in both stages. The speed up strategy is applied to the solution of the thermal partition in the first stage.

This procedure allows speeding up the entire simulation while visualizing the material flow and the process forces and moment with the movement of the asymmetrical pin. Note that the asymmetrical pin-workpiece interface is constantly changing with time; thus performing a transient simulation is indispensable.

The first stage results in drastically reducing the CPU time required to reach the steadylike state. The transient stage is accelerated by modifying the thermal inertia term in the 
energy balance equation. This is achieved introducing an acceleration parameter, $\alpha$, that increases the thermal diffusion:

$$
\rho_{0} c\left(\frac{1}{\alpha} \frac{d T}{d t}+\left(\mathbf{v}-\mathbf{v}_{\text {mesh }}\right) \cdot \nabla T\right)+\nabla \cdot \mathbf{q}=D_{\text {mech }}
$$

This leads to a 'speed-up' transient stage that reaches the steady-state temperature field in a reduced number of time-steps.

The optimal value of the parameter $\alpha$ depends on the degree of thermo-mechanical coupling. For totally uncoupled thermal and mechanical partitions in Table 1, parameter $\alpha=\infty$ could be used to obtain the thermal steady state without the need of time stepping. But the FSW process is strongly coupled in three ways: (i) the convection velocity $\mathbf{v}$ in Eq. (1) comes from the mechanical problem; (ii) the source term $D_{\text {mech }}$ in Eq. (1) also comes from the mechanical problem, and (iii) the mechanical properties and the constitutive model are very temperature dependent.

Therefore, the speed-up factor $\alpha$ has to be large enough to speed up the simulation and small enough to allow for convergence of the strong thermo-mechanical coupling. Practically applicable values for the parameter are in the range $\alpha=50-500$.

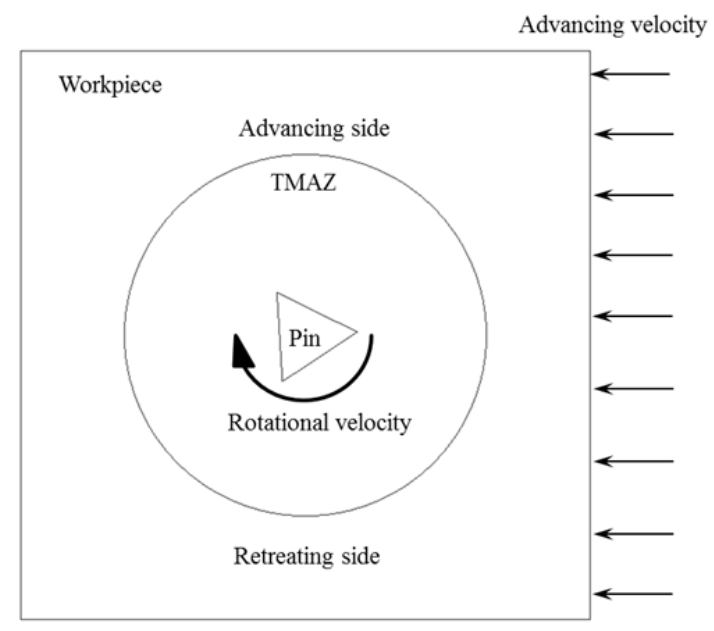

Figure 1: Domain splitting used for the analysis 


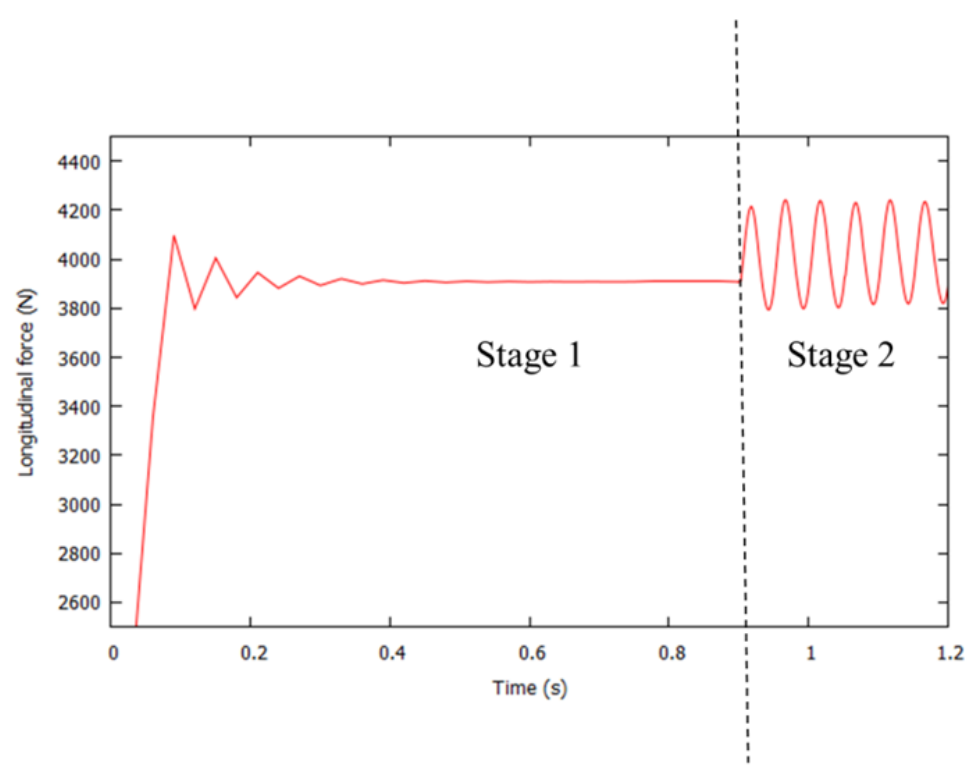

Figure 2: Longitudinal force versus time in a two-stage simulation (stage1: speed-up and stage 2: periodic)

To demonstrate the effect of the speed up $\alpha$ parameter, table 2 shows the reduction of CPU time required to reach the steady-state using different values for $\alpha$ in a 2D FSW simulation with circular pin, similar to the ones discussed in section 5. Figure 3 shows the corresponding evolution of the computed values for the torque moment.

Table 2: Reduction of CPU time in order to reach the steady-state with different $\alpha$ parameters.

\begin{tabular}{|l|l|}
\cline { 2 - 2 } \multicolumn{1}{l|}{} & CPU time to reach steady -state \\
\hline$\alpha=1$ & $>40 \mathrm{~min}$ \\
\hline$\alpha=10$ & $10 \mathrm{~min}$ \\
\hline$\alpha=100$ & $<3 \mathrm{~min}$ \\
\hline
\end{tabular}

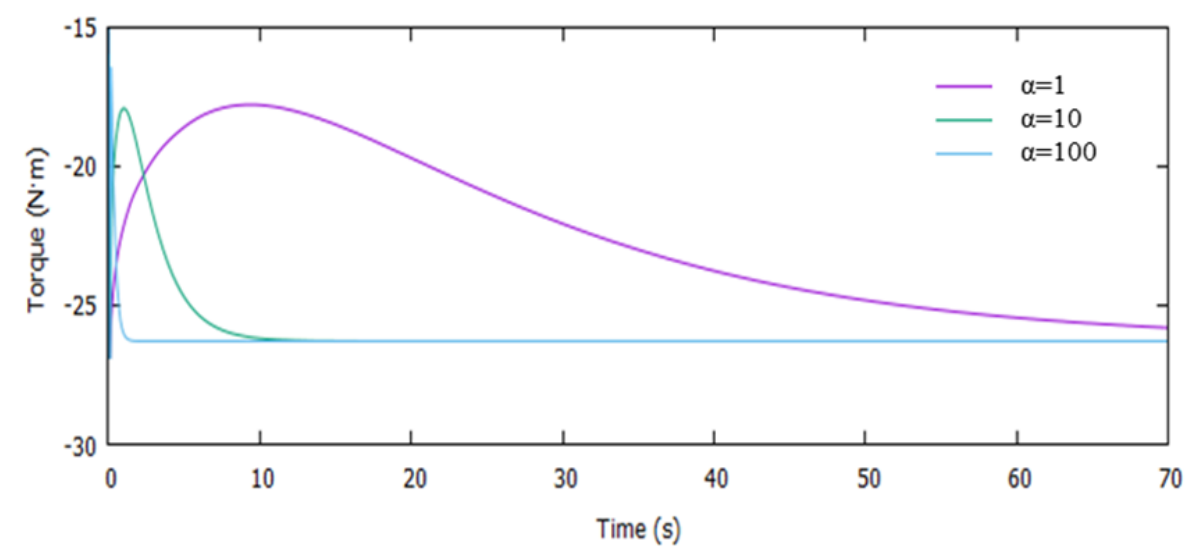

Figure 3: Evolution of computed torque moment obtained with 3 different speed up $\alpha$ coefficients

In the first stage, only the Eulerian formulation is used, and the ALE framework is not considered in the pin and TMAZ $\left(\mathbf{v}_{\text {mesh }}=\mathbf{0}, \alpha>1\right)$. Therefore, there is no periodic stage, but a pseudo-steady stage which is attained with the speed-up procedure (Figure 2). 
In the second stage, the ALE framework is considered in the pin and TMAZ, with the mesh velocity equal to the tool rotational velocity $\left(\mathbf{v}_{\text {mesh }}=\omega \times \mathbf{r}, \alpha=1\right)$. Therefore, there is a real periodic stage to be simulated (Figure 2).

Figure 4 illustrates the comparison of the two-stage speed up strategy with the standard single stage procedure. It is noticeable that the speed up strategy reaches the same steady-state condition at a much reduced computational cost. In practical terms, the number of time steps necessary in the first stage is comparable to the number of step required to perform one single revolution. As about 50 revolutions are necessary to reach close to steady-state values in the single-stage strategy, the computational savings, without loss of accuracy, are outstanding.

Figure 5 shows that the temperature field follows a similar trend as the mechanical one and that the steady state temperature obtained with both strategies is the same.

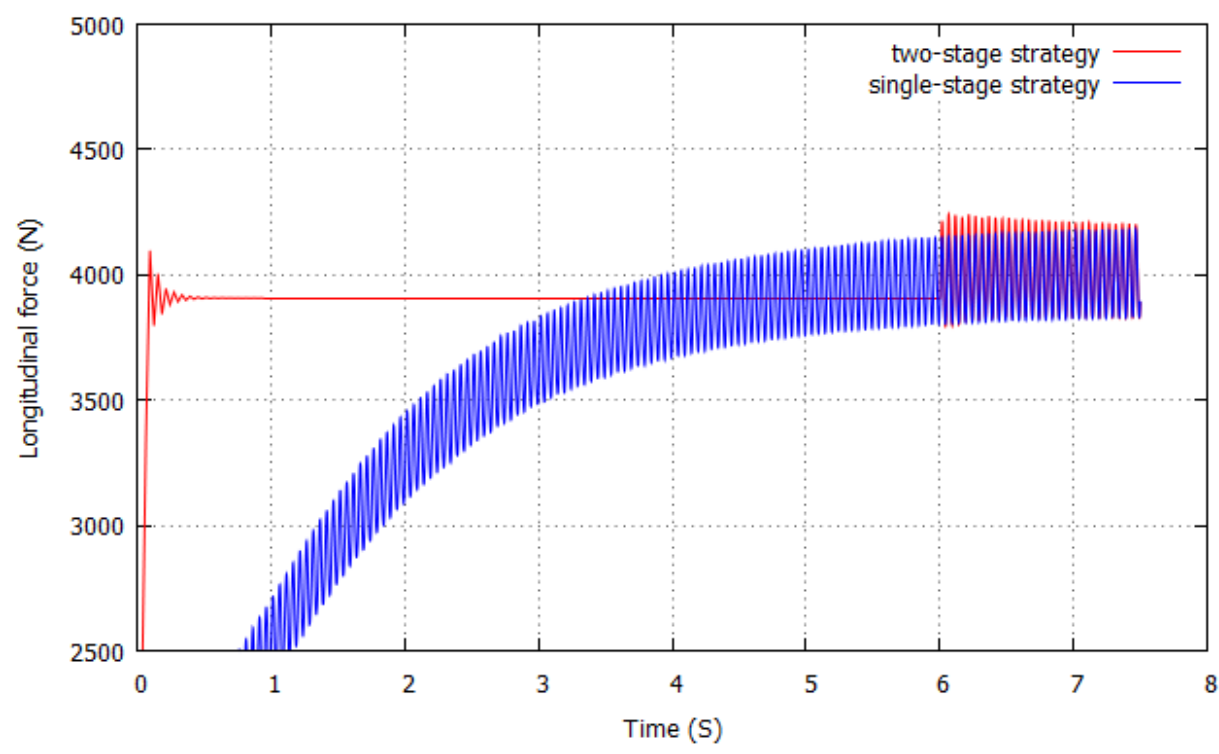

Figure 4: Longitudinal force versus time in two-stage and single-stage simulations 


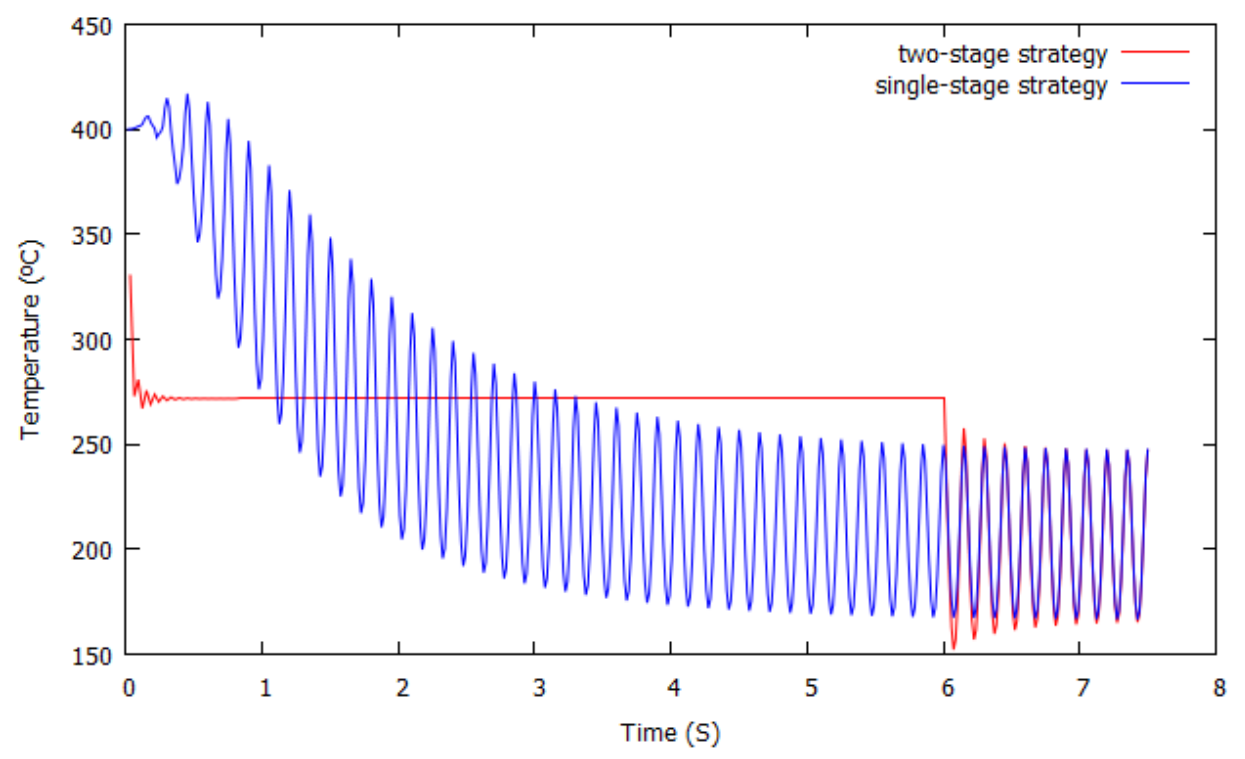

Figure 5: Temperature evolution at one point of the weld line in two-stage and single-stage simulations

In this work, the FSW problem in equation (1) is defined in terms of the velocity field as it is set in Eulerian and ALE frameworks. Accordingly, the material behaviour is depicted by very high strain rates, a vast temperature range and non-Newtonian constitutive laws.

Different rate-dependent constitutive models can be implemented for modelling the FSW process. In the present work, piecewise linear Norton-Hoff model is considered (see next section).

In order to deal with the isochoric behaviour of the material flow during the FSW process, a mixed velocity-pressure-temperature FE technology is used to solve the problem [5-7]. The problem starts at room temperature and reaches the steady-state defined by temperature, velocity and pressure fields. The coupled thermo-mechanical problem is solved using a staggered time-marching algorithm where the thermal and mechanical sub-problems are solved sequentially, applying the classical fractional step method. At each time step, the nonlinear mechanical problem with visco-plastic constitutive model and temperature-dependent properties is solved first, at constant temperature, until the convergence is achieved. Then, the thermal problem is solved, keeping the mechanical variables (velocity and pressure) constant. 


\section{Piecewise linear constitutive model}

The Norton-Hoff constitutive model [2-7] is suited for the materials that are highly rate sensitive. It accurately describes the mechanical properties of the materials used in FSW and its parameters can be obtained in simple mechanical tests with significant viscous and creep response to loading. The Norton-Hoff constitutive model can be written as

$$
\sigma_{e q}\left(\dot{\varepsilon}_{e q}, T\right)=\sqrt{3} \mu(T)\left(\sqrt{3} \dot{\varepsilon}_{e q}\right)^{m(T)}
$$

where $\sigma_{e q}=\sqrt{3 / 2}(\mathbf{s}: \mathbf{s})^{1 / 2}, \quad \dot{\varepsilon}_{e q}=\sqrt{2 / 3}(\dot{\varepsilon}: \dot{\varepsilon})^{1 / 2}, \mu(T)$ and $m(T)$ are the equivalent stress, equivalent strain rate, viscosity parameter and viscosity exponent, respectively.

The model generates heat by mechanical plastic dissipation, $\left(D_{\text {mech }}\right)$ defined by the product of the deviatoric part of the stress and the strain rate (Table 1).

The Norton-Hoff constitutive model captures the strong non-linearity of the mechanical behaviour, and this implies harsh numerical difficulties, especially at low (cold) temperatures due to the high (unbounded) viscosity. These difficulties appear in the transition between the solid and mushy-phase formed close to the pin in the TMAZ.

The Norton-Hoff model is cumbersome to linearize, as the derivatives of the constitutive equation are also dependent on the strain-rate and the temperature. This reflects on convergence difficulties of the numerical implementation. Firstly, the optimal convergence rate is difficult to achieve and, secondly, this yields an inefficient performance of the solver.

In order to enhance the convergence rate of the highly non-linear and coupled problem, a feasible approach is to assume a piecewise linearized Norton-Hoff model for different temperatures and strain rate values in a logarithmic scale. Thus, instead of using the original non-linear stress- strain rate curves at each temperature, piecewise linearized curves are employed (see Figure 6).

The relevant strain rate values defining each segment of the linearized model are taken as powers of 10, according to the typical experimental measurements. Hence, strain rates of $10^{-2}, 10^{-1}, 1,10^{1}, 10^{2} \ldots[\mathrm{sec}]^{-1}$ are selected to define the piecewise liner model. This a-priory linearization of the model, considering constant viscosity for each strain rate interval, allows for alleviating the number of iterations needed for convergence, reducing the CPU time drastically. 

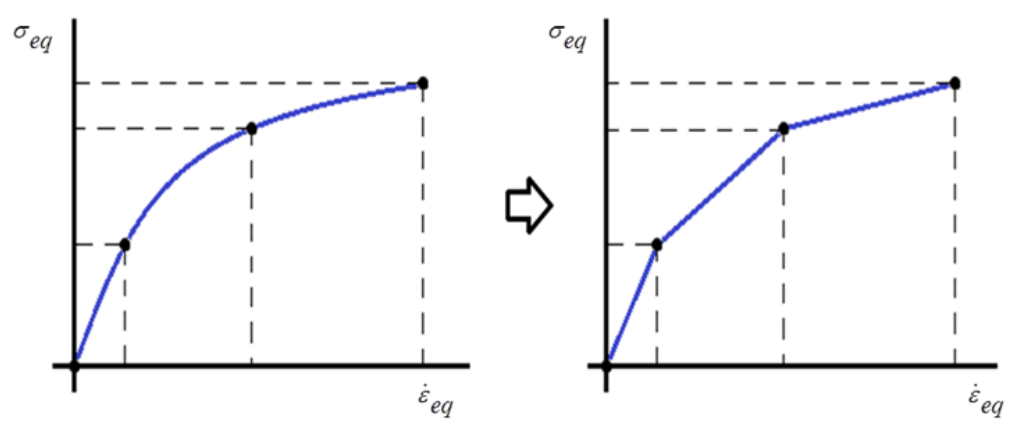

Figure 6: Scheme of a piecewise linearization of a function

As an example, in a 2D FSW simulation with circular pin similar to the ones presented in section 5, the CPU time is more than halved (see table 3, speed up methodology is applied in both cases).

Table 3: Total CPU times comparing Classic and Piecewise Linear version of Norton-Hoff models

\begin{tabular}{|r|l|}
\hline \multicolumn{2}{|c|}{ TOTAL CPU TIME [min] } \\
\hline Classic NortonHoff & 7 \\
\hline Piecewise Linear NortonHoff & 3.2 \\
\hline
\end{tabular}

\section{Enhanced friction law at the Pin-workpiece interface}

A key point in FSW simulations is the friction model used between the tool and the workpiece. The real sliding contact conditions are necessarily between two extreme limit cases: either perfect stick (the material at the contact interface sticks to the tool surface) or perfect slip. The representation of the interaction between the tool and the workpiece is essential for accurate estimation of the heat generation during FSW process. Therefore, together with the material stirring, the friction mechanism is the main source of heat to allow for welding.

In a perfect stick situation, friction does not occur as no relative movement between the two surfaces in contact takes place. Hence the heat is generated by the material stirring process (plastic dissipation), only.

In a sliding situation, there exists a relative velocity between tool and workpiece, and thus heat is generated by friction as well. In this case, the stirring process is less pronounced than in the stick case.

In a perfect sliding situation, the relative velocity between tool and workpiece is maximum and no interfacial shear stress exists.

Typically, stick/slide condition will depend on the materials in contact, the rotation speed, the pin/shoulder threading, etc. leading to different frictional mechanisms. 
This work aims at analysing the FSW process at both limit cases of fully stick and fully slip conditions. To this end, a thermo-mechanical Norton's friction model is used. In it, the tangential component of the traction vector at the contact interface, $\boldsymbol{t}_{T}$, is defined as:

$$
\boldsymbol{t}_{T}=a(T)\left\|\Delta \mathbf{v}_{T}\right\|^{q} \mathbf{u}_{T}
$$

where $a(T)$ is the (temperature dependent) material consistency parameter, $0 \leq q \leq 1$ is the strain rate sensitivity and $\mathbf{u}_{T}=\frac{\Delta \mathbf{v}_{T}}{\left\|\Delta \mathbf{v}_{T}\right\|}$ is the tangential unit vector, defined in terms of the relative tangential velocity at the contact interface, $\Delta \mathbf{v}_{T}$.

The two limiting cases investigated in this work correspond to:

- Stick case $a=\infty$

- Slip case $a=0$

The heat flux produced by the frictional contact is [27]

$$
\left\{\begin{array}{l}
q_{\text {frict }}^{\text {pin }}=\vartheta^{\text {pin }}\left(\mathbf{t}_{T} \cdot \Delta \mathbf{v}_{T}\right) \\
q_{\text {frict }}^{S Z}=\vartheta^{S Z}\left(\mathbf{t}_{T} \cdot \Delta \mathbf{v}_{T}\right)
\end{array}\right.
$$

where the amount of heat absorbed by the pin-tool, $\vartheta^{\text {pin }}$, and by the workpiece, $\vartheta^{S Z}$ (at the stir-zone), depends on the thermal diffusivity, $\gamma=\frac{k}{\rho_{o} c}$, of the two materials in contact as:

$$
\left\{\begin{array}{l}
\vartheta^{p i n}=\frac{\gamma^{p i n}}{\gamma^{p i n}+\gamma^{S Z}} \\
\vartheta^{S Z}=\frac{\gamma^{S Z}}{\gamma^{p i n}+\gamma^{S Z}}
\end{array}\right.
$$

Note that the frictional heat flux is null in the limit cases of slip and stick, but not in the intermediate cases, where the general formulation applies.

For partially sticking conditions, the same considerations about the speed-up parameter $\alpha$ apply. Frictional contact (i) affects the velocity field, (ii) contributes to the mechanical dissipation and (iii) the friction parameters may be temperature dependent, as those in the material constitutive model. This is not a further limitation to the use of the twostage strategy. 


\section{Analysis of the pin tool profile}

In this section, the effect of pin tool profile on metal flow, torque and forces during friction stir welding is studied.

The simulation is carried out using the in-house finite element code COMET [25] developed by the authors, incorporating the proposed two-stage speed-up strategy for performing the analysis.

A 2D square shaped aluminium workpiece $44 \times 44 \mathrm{~mm}^{2}$ is considered in conjunction with a set of typical tool geometries: circular, triflute, trivex and triangular (Figure 7(a)). They are all manufactured from a circular pin of $8 \mathrm{~mm}$ in diameter.

All the cases studied share the same process parameters: advancing and rotational velocities of $400 \mathrm{~mm} / \mathrm{min}$ and $400 \mathrm{rpm}$, respectively.

The material behaviour of the considered aluminium alloy (A16063-T6) is presented in figure 8. Material characterization from experimental tests is given in terms of stress/strain rate or, equivalently, viscosity/strain rate within a temperature range varying from $350-575^{\circ} \mathrm{C}$. The values for temperatures outside of the experimental range $\left(350-575^{\circ} \mathrm{C}\right)$ are extrapolated.

The parameters defining the model in the entire temperature range are obtained by fitting the experimental data. These parameters are depicted in figure 9.

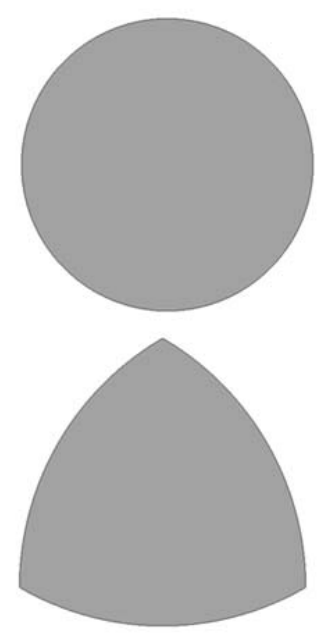

(a)
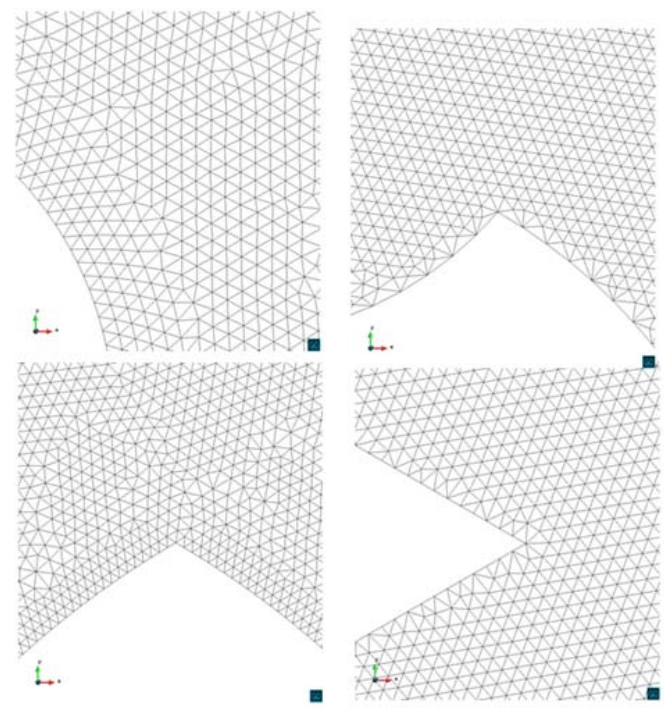

(b)

Figure 7: (a) Various pin shapes (from top left to bottom right: circular, triflute, trivex and triangular) (b) FE meshes close to the pin 


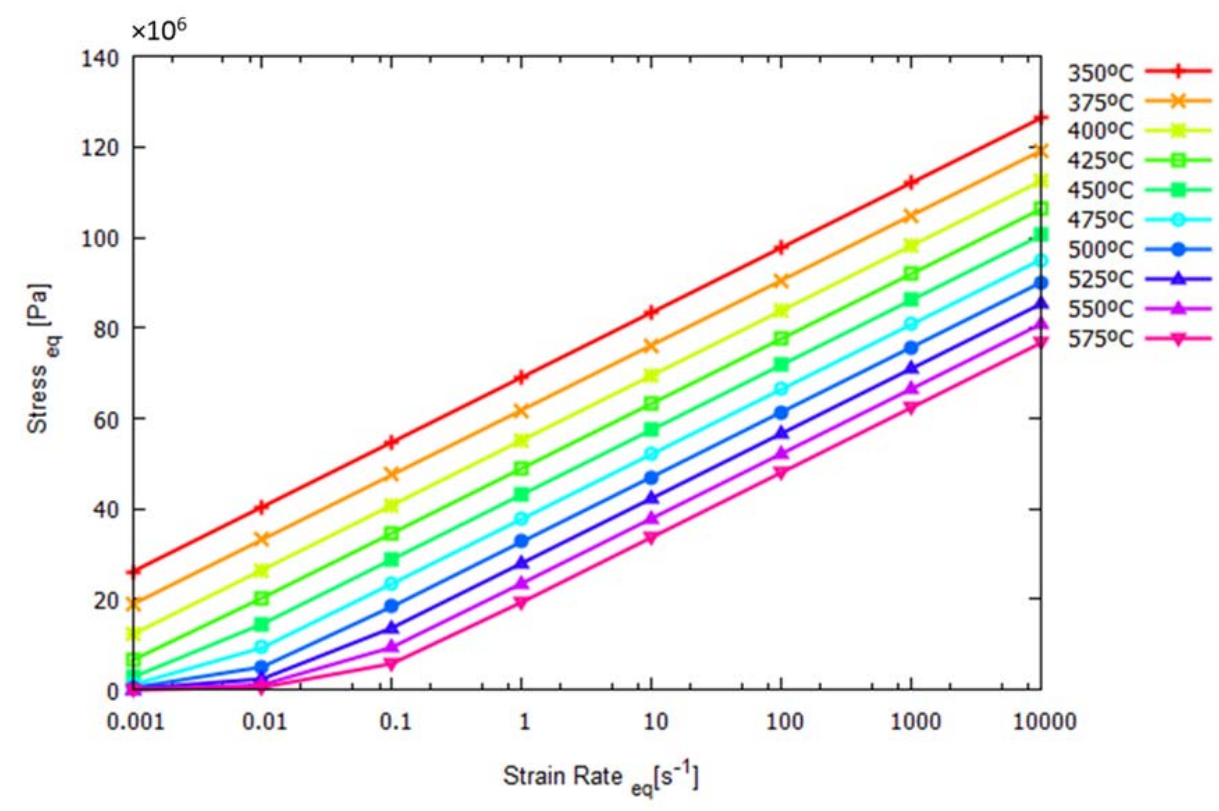

Figure 8: Material characterization (logarithmic scale)

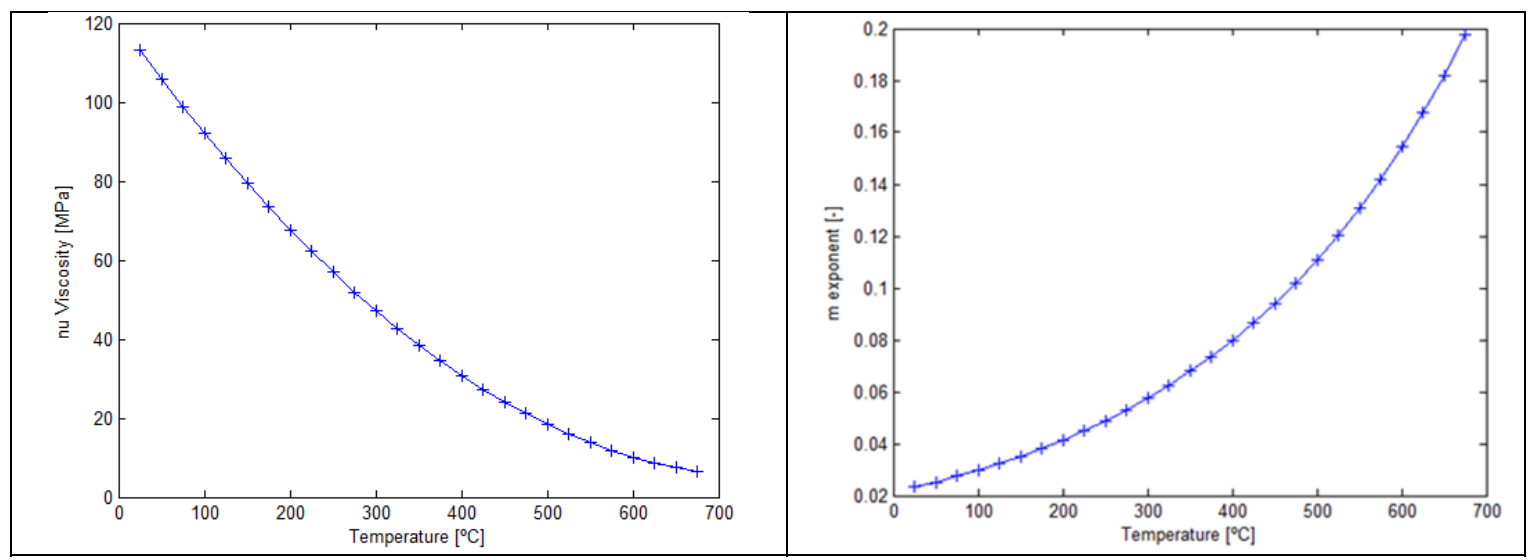

Figure 9: Evolution of viscosity vs. temperature (left) and viscosity exponent vs. temperature (right)

Lateral boundaries of the workpiece are assumed to dissipate heat by convection $\left(q_{\text {conv }}\right)$

as

$$
q_{\text {conv }}=h_{\text {conv }}\left(T-T_{\text {env }}\right)
$$

where $h_{\text {conv }}=500 \mathrm{~W} / \mathrm{m}^{2} \mathrm{~K}$ is the convection coefficient and $T_{e n v}=20^{\circ} \mathrm{C}$.

The $2 \mathrm{D}$ problem is modelled using mixed $\boldsymbol{v} / p$ linear triangular elements. A zoom-in of the FE meshes in the area close to the pin is shown in figure $7(\mathrm{~b})$. The meshes are specifically designed for simulating the FSW welding stage, with finer discretization in the stir ring region. The numbers of elements and nodes at the meshes are listed in table 4. 


\begin{tabular}{|c|c|c|c|c|}
\hline \multicolumn{5}{|c|}{ MESH DETAILS } \\
\hline Pin profile & Circular & Triangular & Triflute & Trivex \\
\hline Number of nodes & 47414 & 50785 & 48139 & 50597 \\
\hline Number of elements & 94488 & 101336 & 96044 & 100960 \\
\hline
\end{tabular}

Results are presented for two limit cases of frictional contact between pin and workpiece: slip and stick.

Slip conditions are recovered when the friction coefficient is zero. In this case, there is perfect sliding between the surfaces in contact, with no shear traction acting between them. The movement of the material around the pin depends only on the features and shape of the pin itself. Heat is generated by plastic dissipation only.

Stick conditions occur for very high values of the friction coefficient. In this case, there is no sliding between the surfaces in contact. The material sticks to the pin and moves together with it. Also in this case, heat is generated by plastic dissipation only. The shear traction between the contact surfaces is defined by the shear strength of the material of the workpiece at the temperature of the contact. In the case of steel pin and aluminium workpiece, this hypothesis is commonly used. Moreover, when the tool pin and the shoulder surfaces are designed with threads, the material surrounding the tool tends to be trapped in-between. Thus, no sliding between the tool and the workpiece exists, and stick conditions can be assumed.

To analyse the effect of the contact conditions and pin shapes, contour fills for temperature, J2 strain rate and J2 stress are depicted in Figures 10, 11 and 12. The maximum values of each of these quantities are given in table 5. The results presented correspond to the second stage of the simulation when the periodic state is achieved.

In all the figures, the profiles for a) circular, b) triflute, c) trivex and d) triangular pins are shown.

Figure 10 shows temperature contour fills for the slip and stick cases. The hottest zone of the workpiece varies in shape and size depending on the pin profile. In all but the triangular case, the heat generated in the slip cases is much smaller than in the corresponding stick cases. As the circular pin has no sharp corners, the total heat generation in the slip case is negligible. Contrariwise, the effect of the sharp corners in 
the slip case is visible in the other three cases, where stirring of the material occurs exclusively due to the geometry of the pin.

In the stick case with circular pin, the heat generation is the maximum, as this shape has the maximum possible contact area between the pin and the workpiece. Therefore, the amount of workpiece material affected by the movement of the pin is the largest. This trend is similarly observed in the experimental results presented in [28] for polygonal and circular pins and in [23] for a conical tool and a triflat tool. In the stick case, the effect of the various pin shapes on the temperature field is not as clear as for the slip case (very close to each other at around $400^{\circ} \mathrm{C}$ ). This is justified by the $\mathrm{J} 2$ strain rate results displayed in figure 11. Higher temperature gradients lead to higher thermal stresses and, consequently higher deformations. In the stick case, the J2 strain rate patterns are similar for all the considered shapes, revealing the formation of a circular band around the pin. Analogous behaviour is also observed in the slip case for the triangular pin due to the extreme sharpness of the corners.

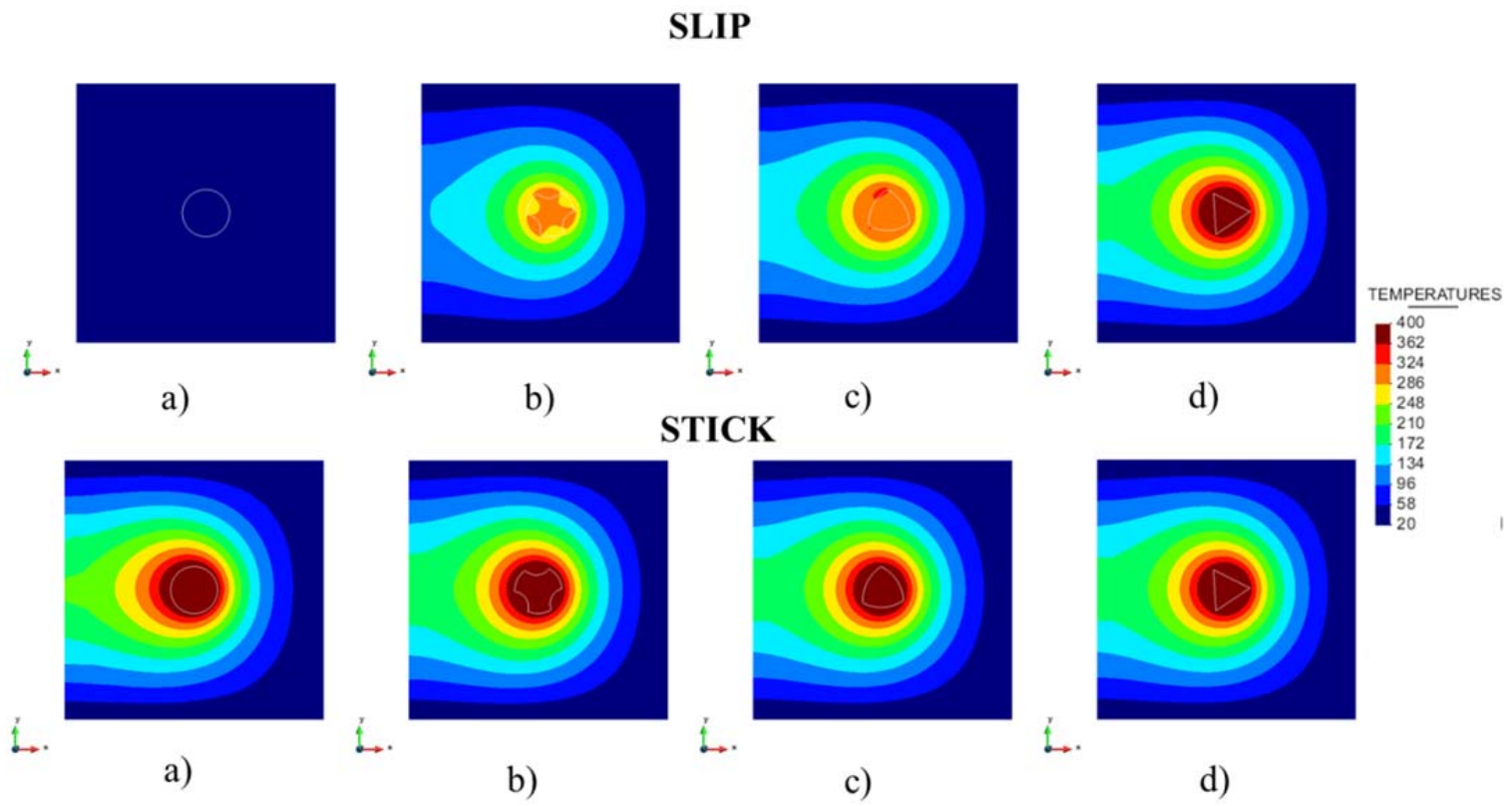

Figure 10: Temperature contour fills at periodic state: a) circular, b) triflute, c) trivex and d) triangular pins 


\section{SLIP}
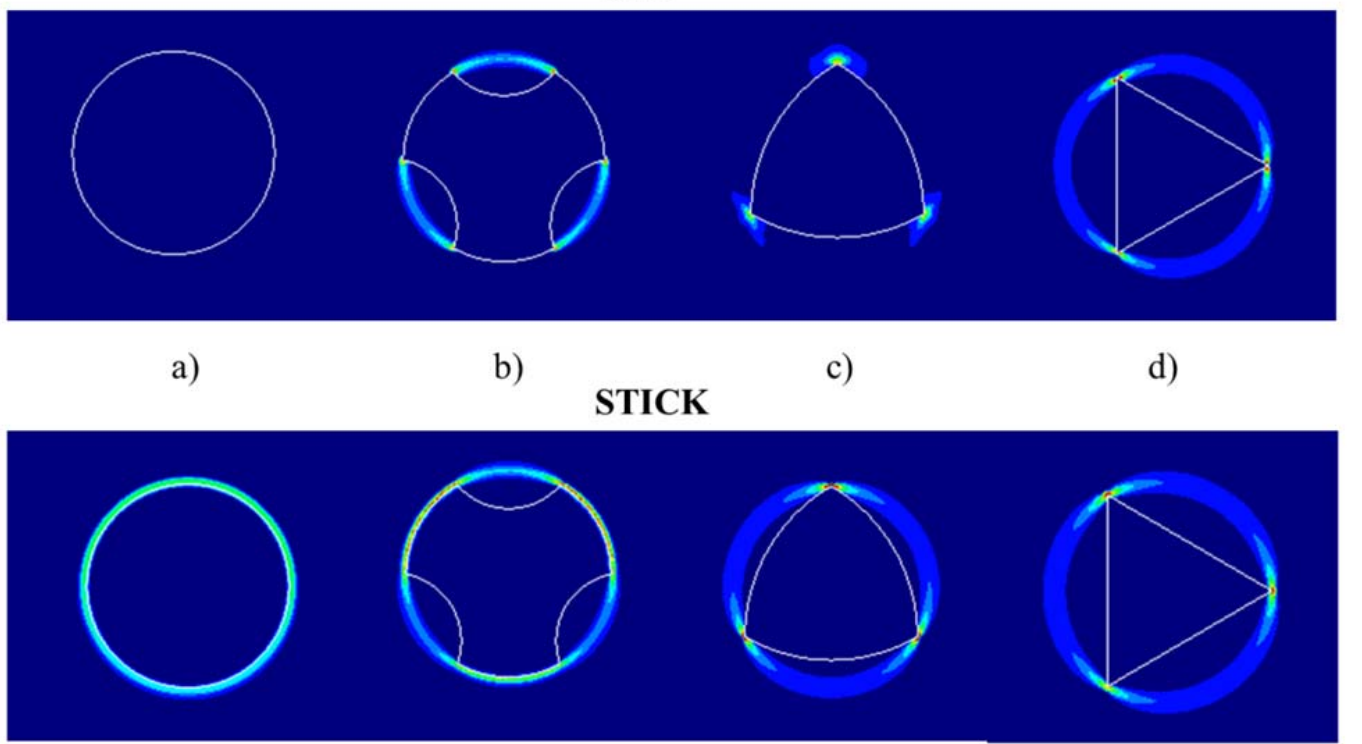

a)

b)

c)

d)

Figure 11: J2 strain rate contour fills at periodic state: a) circular, b) triflute, c) trivex and d) triangular pins

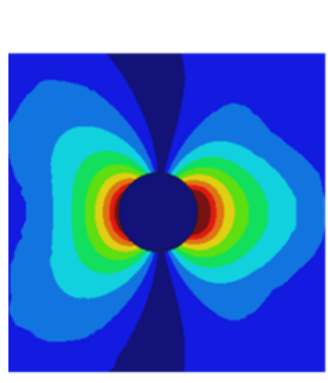

a)

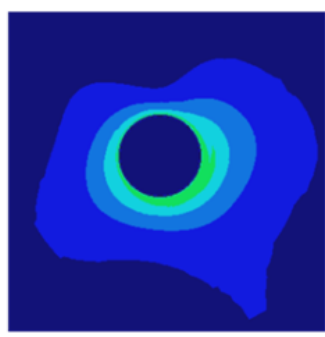

a)

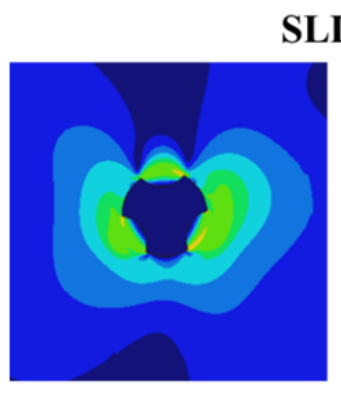

b)

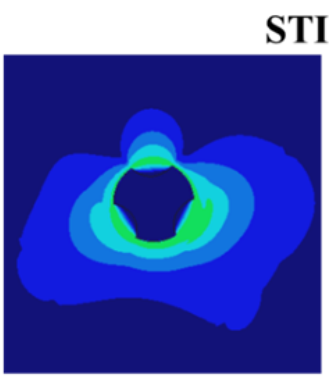

b)

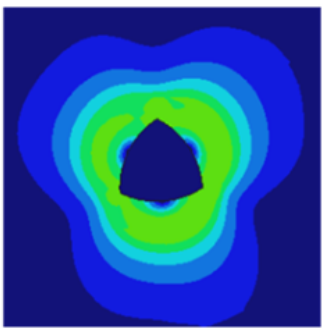

c)

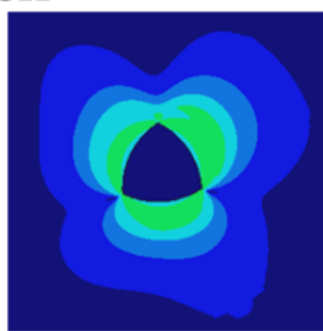

c)

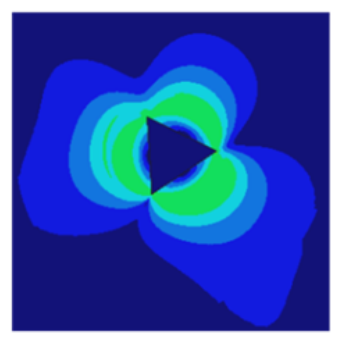

d)

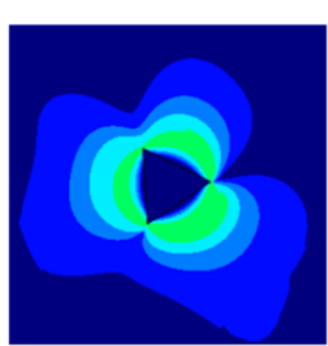

d)

Figure 12: J2 stress contour fills at periodic state: a) circular, b) triflute, c) trivex and d) triangular pins 


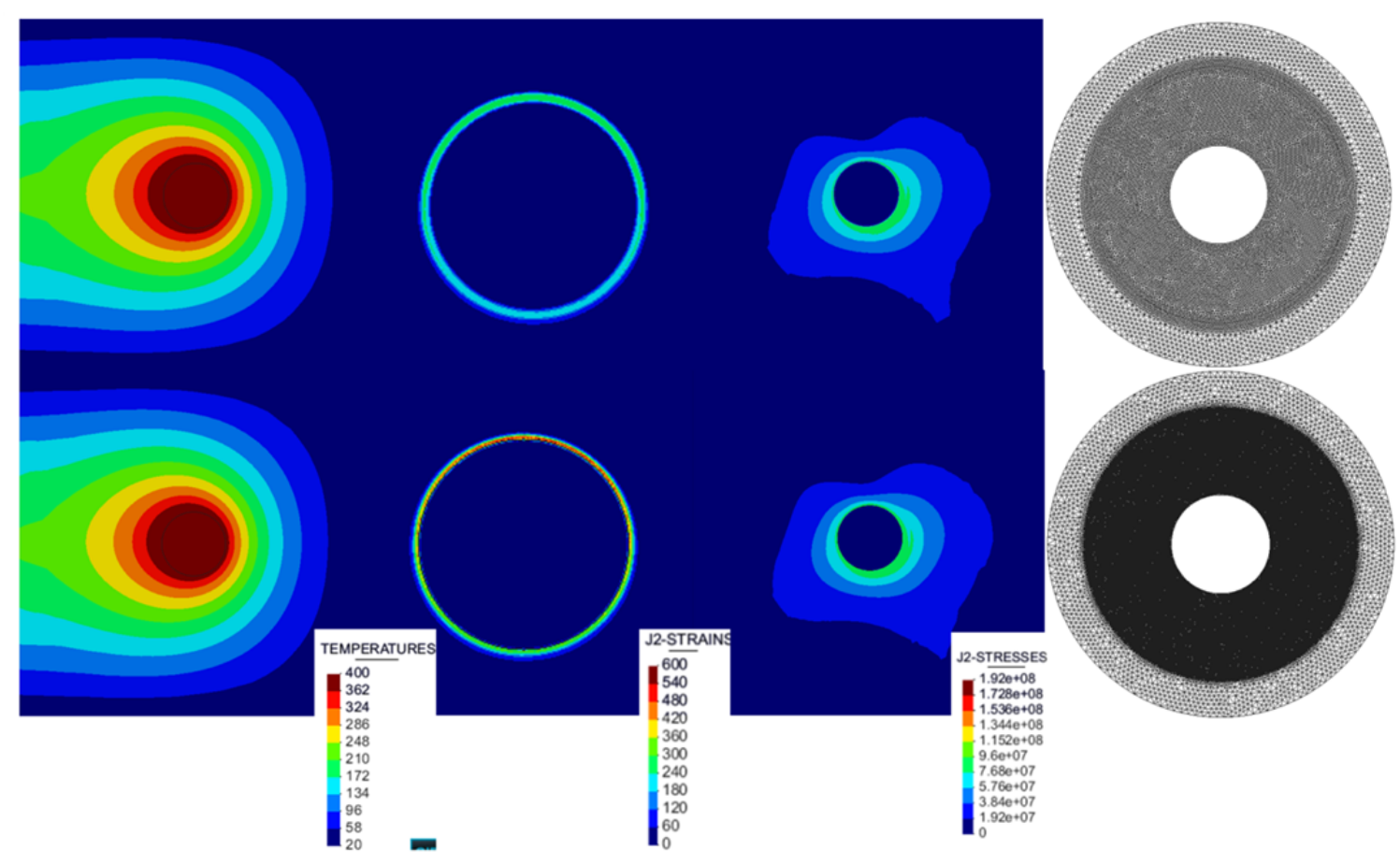

Figure 13: Temperature, $\mathrm{J} 2$ strain rate and $\mathrm{J} 2$ stress contour fills for the fine and finer meshes

Figure 11 shows that in FSW the strain rate is highly localized. In finite element simulations, the maximum strain rates are localized in the layer of elements closer to the tool and, on the one hand, higher values are obtained if smaller elements are used around the pin; on the other hand, the corresponding plastic dissipation and heat generation occurs in a thinner layer. Figure 13 shows that, for the circular case, identical results are obtained in terms of temperatures and J2 stress with two different meshes; the strain rates in the finer mesh increase with respect the other one in the same ratio as the element size decreases.

Table 5: The results for different pin shapes and limit friction conditions

\begin{tabular}{|c|c|c|c|c|c|c|c|c|}
\hline & \multicolumn{2}{|c|}{ Circular } & \multicolumn{2}{|c|}{ Triflute } & \multicolumn{2}{|c|}{ Trivex } & \multicolumn{2}{|c|}{ Triangular } \\
\hline & slip & stick & slip & stick & slip & stick & slip & stick \\
\hline Temperature $\left({ }^{\circ} \mathrm{C}\right)$ & 36.5 & 415 & 309 & 408 & 331 & 397 & 389 & 398 \\
\hline J2-Strain rate $\left(\mathrm{s}^{-1}\right)$ & 1.0 & 284 & 576 & 656 & 496.5 & 1024 & 768 & 665 \\
\hline J2-Stress (MPa) & 192 & 91 & 129 & 93.2 & 115 & 97.5 & 101 & 95 \\
\hline
\end{tabular}

The $\mathrm{J} 2$ stress distributions are presented in figure 12 . The greater is the slip between the pin and the workpiece, the larger the J2 stress. Comparing the different pin profiles, the circular pin in slip and stick cases has the largest and the smallest slip behaviour, respectively, which correspond to the largest and the smallest J2 stress values. 
The streamlines (figure 14) reveal that the flow is similar for the circular and triflute pins, on the one hand, and the trivex and triangular pins, on the other. In the slip case, comparing the circular and triflute cases, the pins are obstacles and the flow passes over them, even though the segments of the triflute pin unsuccessfully intend to create the joint. In the stick case, the effect of the segments is not visible, as the material is trapped in-between and thus the pin effect is quite similar to that of a circular pin. Comparing the trivex and triangular pins in the slip case, the sharp corners of the cross section help to generate the higher temperatures that allow the weld creation; this effect is more evident in the triangular case. The triangular pin in the slip and stick cases shows very similar results.

\section{SLIP}

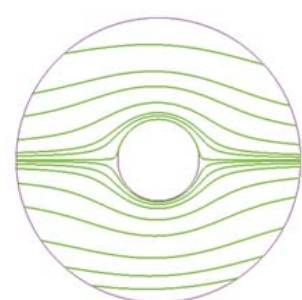

a)

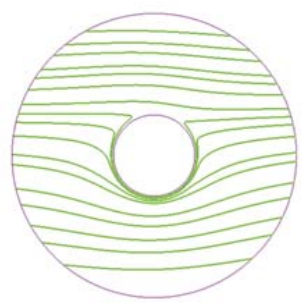

a)

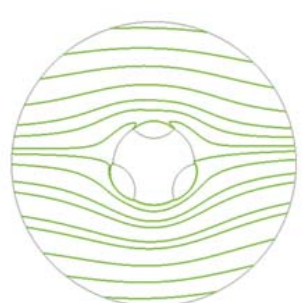

b)

STICK

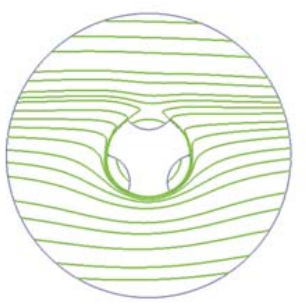

b)

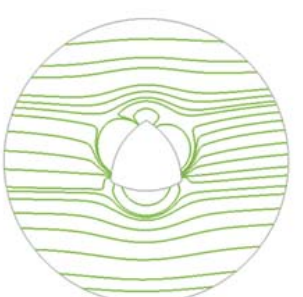

c)

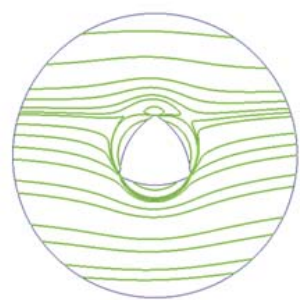

c)

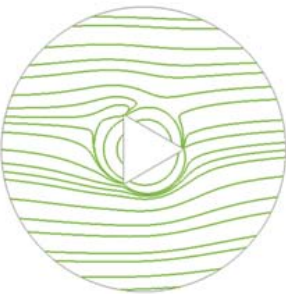

d)

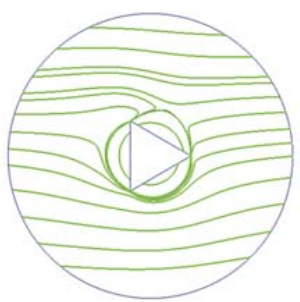

d)

Figure 14: Stream lines around the pins: a) circular, b) triflute, c) trivex and d) triangular pins

The effect of the distinct pin shapes is also visualized by using material particle as flow tracers (figure 15). The tracking of the material particles is performed using the transient second stage of the analysis, once the periodic state is achieved. The material particles are initially located ahead of the pin and perpendicular to the weld line in two colours. Their positions at each time-step of the analysis are obtained using a particle tracing technique [10]. Firstly, a spatial search algorithm is required to find the element surrounding the material particle and, secondly, its velocity is interpolated from the 
values of the velocity field at the nodes of this element. To find the position of the material particles, the 4-th order Runge-Kutta (RK4) time integration scheme is used.

Initial position

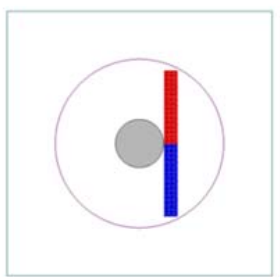

a)

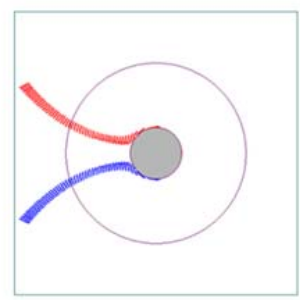

a)

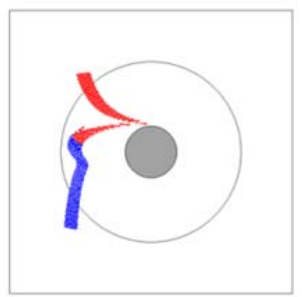

a)

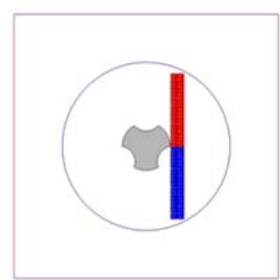

b)

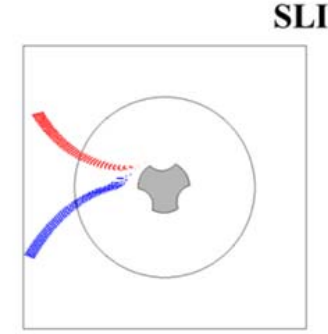

b)

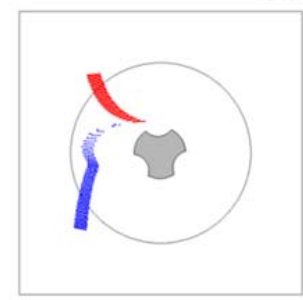

b)

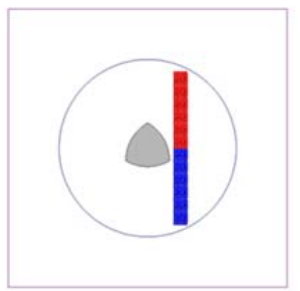

c)

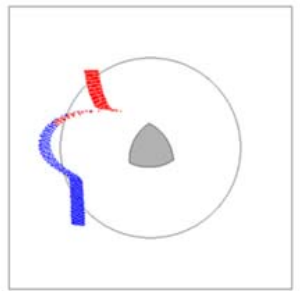

c)

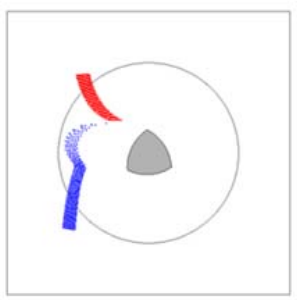

c)

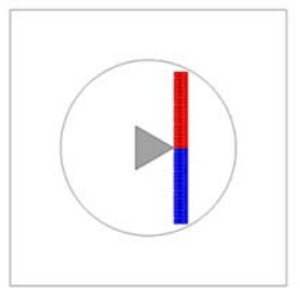

d)

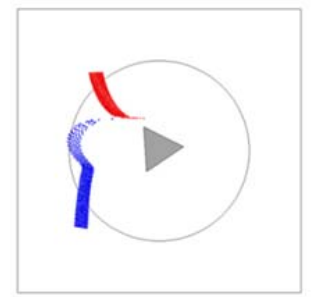

d)

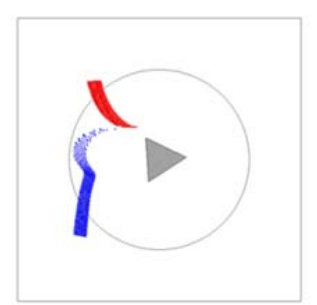

d)

Figure 15: Material particles after weld: a) circular, b) triflute, c) trivex and d) triangular pins

From figure 16, it can be deduced that that the joint is created using most of the considered pin shapes in both slip and stick cases, all except for the circular and triflute pins in the slip case. Using the triangular pin, the slip and stick cases provide a very similar joint. For a trivex pin, the radius of the joint curvature in the slip case is larger than in the stick case.

Table 6 presents values of the longitudinal force, transversal force and torque moment for various pin shapes at the two limit frictional contact conditions. These are computed by proper integration of the tractions acting along the tool boundary. A $5 \mathrm{~mm}$ deep pin is considered. The longitudinal force is the force required to move the pin tool along the faying surface during the welding process. For the same speed, the larger is the pin cross surface, the larger is the contact area and so the higher is the force exerted upon 
the tool. The maximum forces are exerted with the circular pin, for both slip and stick cases, even though in the stick case the difference between the forces in all cases is small.

Table 6: The absolute values of forces and torque using different pin shapes and frictional contact condition

\begin{tabular}{ccccccccc}
\hline & \multicolumn{2}{c}{ Circular } & \multicolumn{2}{c}{ Triflute } & \multicolumn{2}{c}{ Trivex } & \multicolumn{2}{c}{ Triangular } \\
\cline { 2 - 8 } & slip & stick & slip & stick & slip & stick & slip & stick \\
$\begin{array}{c}\text { Longitudinal } \\
\text { force (N) }\end{array}$ & 16101 & 4667 & 8725 & 4447 & 970 & 3934 & 3067 & 3512 \\
$\begin{array}{c}\text { Transversal force } \\
\text { (N) }\end{array}$ & 0.19 & 455 & 709 & 244 & 29.4 & 479 & 547 & 174 \\
Torque (N.m) & 0.0 & 26.9 & 22.7 & 26.7 & 22.6 & 26.1 & 26.2 & 25.5 \\
\hline
\end{tabular}

The longitudinal (drag) force is larger for the triflute pin than for the trivex and triangular pins. The larger longitudinal force is the result of the additional material that is stirred by the segments and an effective increase in the cross sectional area of the pin.

In the stick case, the heat generated by the tool is much higher than in the slip case. Higher temperature lowers the shear strength of the material. Therefore, less longitudinal force is necessary for moving the tool forward.

The transversal (lift) forces are much smaller than the longitudinal forces. The transversal force is due to the lack of symmetry of the contact traction at the head and rear sides of the pin tool. Figure 10 reveals a lower temperature at the head of the pin; thus, the flow stress is higher than that at the rear, where the material is hotter and softer. This asymmetry causes a force on the work piece in the $\omega \times \mathrm{v}$ direction, $\omega$ being the rotational direction of the pin tool and $\mathrm{v}$ the weld direction.

In the slip case, the transversal force is higher when using the triflute pin. This is due to the stirring of the material in contact, causing asymmetric tractions at the contact with colder material ahead and hotter material in the rear of the pin.

No torque exists on the FSW tool using circular pin for the pure slip case. Increase in the tool-workpiece contact area with the pin diameter in the stick case and sharp corners in the slip case lead to higher torques requirement.

To sum up, in the stick case, the required torque and longitudinal force increase with the pin area; for the triangular, trivex, triflute and circular shapes, respectively. In the slip case, the forces and torque are affected by the sharp corners and segments as the 
material trapes into the segments and moves with the sharp corners enhancing the rate of frictional heat generation and the resulting softening of a greater amount of deformed material around the pin surfaces.

\section{3D simulation and shoulder effect}

In the following, a 3D FSW simulation is performed: (i) to assess the effectiveness of the proposed methodology in such a demanding problem, and (ii) to evaluate the costeffectiveness of 2D versus 3D FSW simulations.

The simulation corresponds to a circular pin cross section. Stick conditions are assumed. The 3D model consists of a square shaped aluminium workpiece $44 \times 44 \mathrm{~mm}^{2}$ with $10 \mathrm{~mm}$ depth; the pin is $8 \mathrm{~mm}$ in diameter and $4 \mathrm{~mm}$ in depth. The mesh consists of 406,219 elements and 69,442 nodes. The simulation, using the two-stage strategy, is performed in less than $4 \mathrm{hrs}$ to reach to the final periodic state. Using a single stage strategy the simulation would take 50 times more.

In the $3 \mathrm{D}$ case, the tool includes the pin and the shoulder, both affecting the heat generation and the amount of heat generated by the shoulder effect being higher than that generated by the pin.

Figure 16 depicts temperature contour fills on three mutually orthogonal sections of the 3D problem, one horizontal and two vertical. On the one hand, the horizontal cross section ( $3.5 \mathrm{~mm}$ from the surface of the workpiece) shows that the temperature, $\mathrm{J} 2$ strain rate and $\mathrm{J} 2$ stress contour fills at some depth from shoulder are very similar to those in the $2 \mathrm{D}$ simulation, see figures 10 to 13 . On the other hand, the longitudinal and transversal vertical sections show the significant $3 \mathrm{D}$ effect of the shoulder (see figure $17)$.

The maximum values of temperature, $\mathrm{J} 2$ strain rate and $\mathrm{J} 2$ stress in the horizontal cross section are $397{ }^{\circ} \mathrm{C}, 249 \mathrm{~s}^{-1}, 90 \mathrm{MPa}$, respectively. These values are very similar to those obtained in the 2D model, see Table 5. The maximum values of temperature, $\mathrm{J} 2$ strain rate and $\mathrm{J} 2$ stress in the full 3D model are $433^{\circ} \mathrm{C}, 836 \mathrm{~s}^{-1}, 107 \mathrm{MPa}$, respectively. These higher values correspond to points adjacent to the shoulder, and they are due to the increased stirring of the material induced by the stick condition with the shoulder.

The torque computed in the $3 \mathrm{D}$ case is $68 \mathrm{~N} . \mathrm{m}$, a value larger than in the $2 \mathrm{D}$ case because of the increased friction with the shoulder. The longitudinal and transversal 
forces are $745 \mathrm{~N}$ and $230 \mathrm{~N}$, respectively, smaller values than in the $2 \mathrm{D}$ case because the increased heat generation significantly reduces the flow stress of the material (see Figure 8) in the upper part of the too and reduces the overall stresses and the resulting forces.

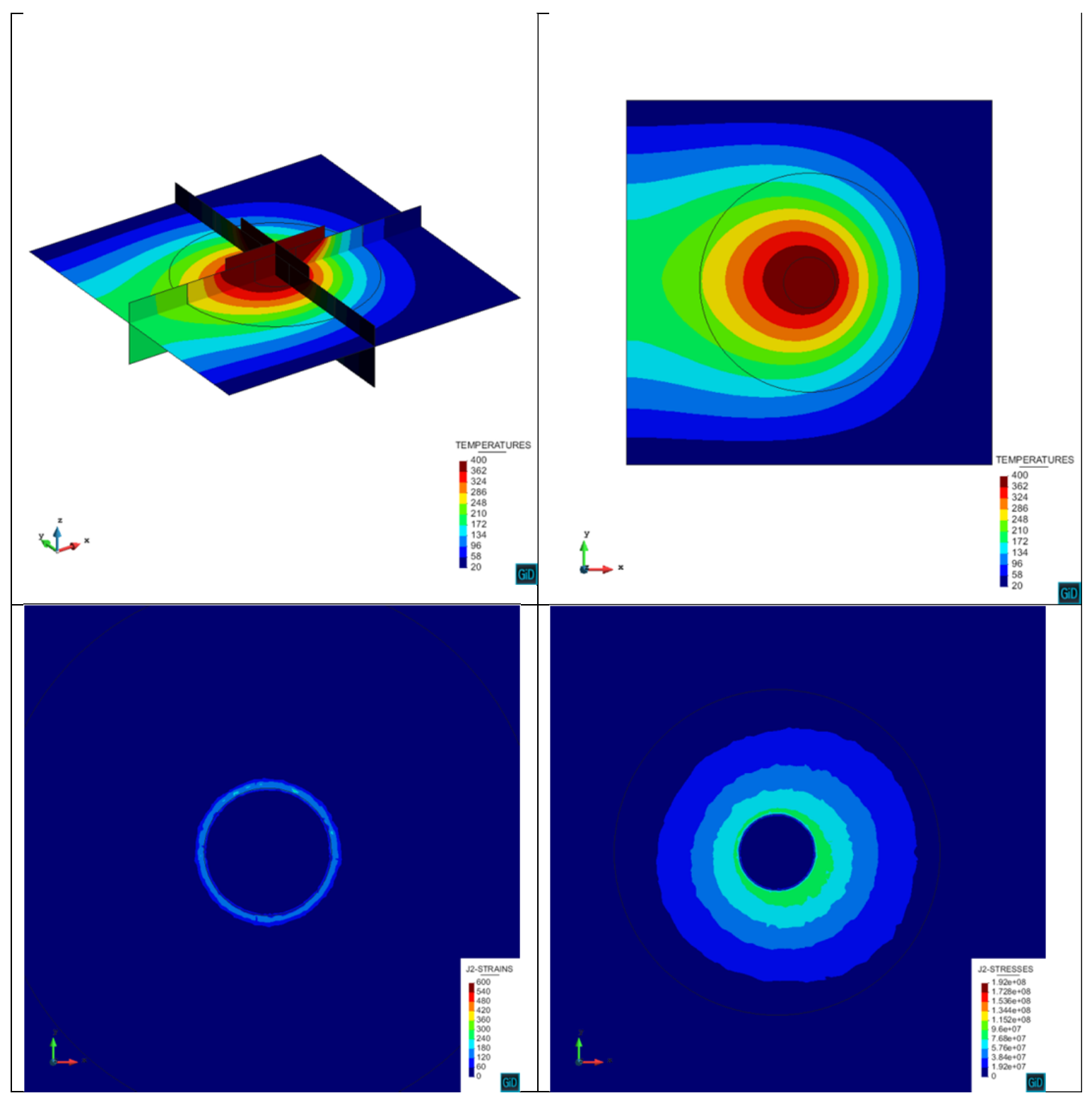

Figure 16: temperature contour fill on cross sections in 3 orthogonal planes and reference axes (top-left) and temperature contour fill ( top-right), J2 strain rate (bottom-left) and J2 stress (bottom-right). 

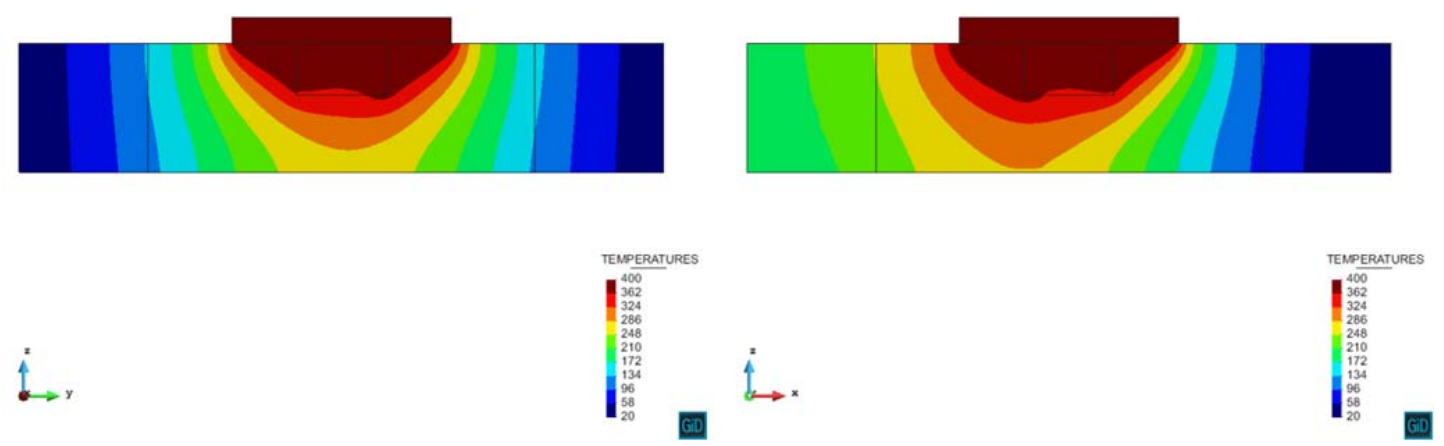

Figure 17: temperature contour fills: a cross section in the $\mathrm{YZ}$ plane (left) and a cross section in the XZ plane (right)

\section{Conclusion}

In this work, a piecewise linearized Norton-Hoff constitutive model and a two-stage strategy are developed and applied to study the effects of the tool geometry upon the FSW processes.

The proposed methodology reduces significantly the computational time and cost while preserving the accuracy of the results. 2D and 3D FSW simulations are performed and their relative cost-effectiveness is evaluated.

The analysed outputs include the longitudinal and transversal forces, torque, temperature distribution, $\mathrm{J} 2$ stress and strain rate, pressure, streamlines and material flow.

The effect of the pin shape on the torque is very similar to that on the forces in the stick case. The transversal forces are much smaller than the longitudinal forces.

It is observed that the flow trend is similar for the circular and triflute pins, on the one hand, and the trivex and triangular pins, on the other. Features such as flutes on the pin increase heat generation due to larger interfacial area; this increases the temperature, reduces the flow stress and boosts material flow. 
In the perfect stick cases:

The larger the pin area is, the higher is the generated heat in the workpiece and the higher force the tool experiences. However in this case, the temperature field is not significantly different when varying the pin shapes.

No noticeable difference is observed in the strain rate and streamlines when varying the pin shapes.

$>$ The final shape of the joint appears to be very similar for all the considered pin shapes.

In the perfect slip cases:

$>$ The sharp corners and segments are the cause of heat generation and material deformation in the workpiece. Practically, no heat is generated using a circular pin.

$>$ Pin shape has a strong effect upon strain rate and streamlines. Circular and triflute pins act as obstacles and material flow passes over them.

No joint can be formed using circular and triflute pins. 


\section{References}

[1] Zhao Y.-H., Lin S.-B., Qu F.-X. and Wu L. (2006) Influence of pin geometry on material flow in friction stir welding process, Materials Science and Technology 22(1):45-50.

[2] Agelet de Saracibar, C., Chiumenti, M., Cervera, M., Dialami, N. and Seret, A. (2014) Computational modeling and sub-grid scale stabilization of incompressibility and convection in the numerical simulation of friction stir welding processes. Archives of Computational Methods in Engineering, 21(1): 3-37.

[3] Chiumenti, M., Cervera, M., Agelet de Saracibar, C. and Dialami, N. (2012) Numerical modeling of friction stir welding processes. Computer Methods in Applied Mechanics and Engineering, 254:353-369.

[4] Dialami, N., Chiumenti, M., Cervera, M. and Agelet de Saracibar, C. (2013) An apropos kinematic framework for the numerical modeling of friction stir welding. Computers and Structures 117:48-57.

[5] Dialami N., Chiumenti M., Cervera M., Agelet de Saracibar C., Ponthot J.-P. and Bussetta Ph. (2014) Numerical simulation and visualization of material flow in Friction Stir Welding via Particle Tracing, Numerical Simulations of Coupled Problems in Engineering, Springer International Publishing, 157-169.

[6] Bussetta P., Dialami N., Boman R., Chiumenti M., Agelet de Saracibar C., Cervera M. and Ponthot J.-P. (2014) Comparison of a fluid and a solid approach for the numerical simulation of Friction Stir Welding with a non-cylindrical pin, Steel research international, 85(6): 968-979.

[7] Bussetta P., Dialami N., Chiumenti M., Agelet de Saracibar C., Cervera M., Boman R. and Ponthot J.-P. (2015) 3D numerical models using a fluid or a solid formulation of FSW processes with a non-cylindrical pin, Adv. Model. and Simul. in Eng. Sci. , 2:27, 1-19.

[8] Yazdipour A., Heidarzadeh A. (2016) Effect of friction stir welding on microstructure and mechanical properties of dissimilar Al 5083-H321 and 316L stainless steel alloy joints, Journal of Alloys and Compounds, 680: 595-603

[9] Leitao C., Arruti E., Aldanondo E., Rodrigues D.M. (2016) Aluminium-steel lap joining by multipass friction stir welding, Materials \& Design 106: 153-160.

[10] Dialami N., Chiumenti M., Cervera M., Agelet de Saracibar C. and Ponthot J.-P. (2013) Material Flow Visualization in Friction Stir Welding via Particle Tracing, International Journal of Metal Forming, 1-15, DOI:10.1007/s12289-013-1157-4. 
[11] Reilly, A., Shercliff, H., Chen, Y., Prangnell, Ph. (2015) Modelling and visualisation of material flow in friction stir spot welding, Journal of Materials Processing Technology 225:473-484

[12] Imaizumi T., Morisada Y., Fujii H., Matsushita M., Ikeda R. (2013) Threedimensional visualization of material flow during friction stir welding for steel and aluminum by two pairs of X-ray transmission systems, Proceedings of the 1 st International Joint Symposium on Joining and Welding, , 359-361

[13] Edwards P. D., Ramulu M. (2015) Material flow during friction stir welding of Ti6Al-4V, Journal of Materials Processing Technology, 218: 107-115

[14] Dialami, N., Cervera, M., Chiumenti, M. and Agelet de Saracibar, C. (2016) Local-global strategy for the prediction of residual stresses in FSW processes, International Journal of Advanced Manufacturing Technology. DOI: 10.1007/s00170-016-9016-3

[15] Zapata J., Toro M., López D. (2016) Residual stresses in friction stir dissimilar welding of aluminum alloys, Journal of Materials Processing Technology, 229: 121127

[16] Dialami, N., Chiumenti, M., Cervera, M. and Agelet de Saracibar, C. (2016) Challenges in thermo-mechanical analysis of Friction Stir Welding processes, Archives of Computational Methods in Engineering, 1-37, http://dx.doi.org/10.1007/s11831-015-9163-y.

[17] Reynolds A. P. and Tang Wei (2001) Alloy, Tool geometry, and Process Parameter Effects on Friction Stir Weld Energies and Resultant Joint Properties, Proceedings of the Symposium on Friction Stir Welding and Processing. p. 15-23, Eds. K. V. Jata, M. W. Mahoney, R. S. Mishura, S. L. Semiatin, and D. P. Field, TMS 2001, Indianapolis, Indiana, November 57.

[18] Hattingh D.G., Blignault C., van Niekerk T.I., James M.N. (2008)“CCharacterization of the influences of FSW tool geometry on welding forces and weld tensile strength using an instrumented tool, Journal of Materials Processing Technology, 203(13):46-57.

[19] Elangovan K., Balasubramanian V.“(2008) Influences of tool pin profile and tool shoulder diameter on the formation of friction stir processing zone in AA6061 aluminium alloy", Materials \& Design, 29( 2): 362-373.

[20] Elangovan K., Balasubramanian V.“ (2008) Influences of tool pin profile and welding speed on the formation of friction stir processing zone in AA2219 aluminium alloy, Journal of Materials Processing Technology, 200(1-3): 163-175. 
[21] Zhao Y.HLin., S.B., Wu L., Qu F.X., (2005) The influence of pin geometry on bonding and mechanical properties in friction stir weld 2014 alloy, Mater. Lett. 59:2948-2952.

[22] Colegrove P.A., Shercliff H.R. (2004)“'Development of Trivex friction stir welding tool Part 1-two-dimensional flow modelling and experimental validation, Science and Technology of Welding \& Joining, 9(4): 345-351.

[23] Su H., Wu Ch., Bachmann M. and Rethmeier M. (2015) Numerical modeling for the effect of pin profiles on thermal and material flow characteristics in friction stir welding, Materials and Design, 77:114-125.

[24] Hasan A.F., Bennett C.J. and Shipway P.H. (2015) A numerical comparison of the flow behaviour in Friction Stir Welding (FSW) using unworn and worn tool geometries, Materials and Design, 87:1037-1046

[25] Cervera M., Agelet de Saracibar C., Chiumenti M. (2002) COMET: Coupled Mechanical and Thermal Analysis, Data Input Manual, Version 5. 0, Technical Report IT-308, http://www.cimne.upc.es

[26] Mahmoud E.R.I., Takahashi M., Shibayannagi T., Ikeuchi K., Effect of friction stir processing tool probe on fabrication of $\mathrm{SiC}$ particle reinforced composite on aluminum surface, Sci. Technol. Weld. Joining 14 (2009) 413-425.

[27] Guerdoux, S., Numerical simulation of the friction stir welding process, $\mathrm{Ph}$. D. thesis, Mines-Paris, 2007.

[28] Mehta M., Reddy G.M., Rao A.V. and De A. (2015) Numerical modeling of friction stir welding using the tools with polygonal pins, Defence Technology, 11(3): 229-236. 